\title{
New Copper and Oxomolybdate Robson-Type Polynuclear Macrocyclic Complexes: Structure, Spectroscopy, and Electrochemical Properties
}

\author{
Marcelo Carpes Nunes, Marcos Antonio Ribeiro, and Fábio Souza Nunes \\ Departamento de Química, Universidade Federal do Paraná, Caixa Postal 19081, 81531-990 Curitiba, PR, Brazil \\ Correspondence should be addressed to Fábio Souza Nunes; fsnunes@ufpr.br
}

Received 3 October 2015; Revised 26 November 2015; Accepted 29 November 2015

Academic Editor: Theocharis C. Stamatatos

Copyright (C) 2015 Marcelo Carpes Nunes et al. This is an open access article distributed under the Creative Commons Attribution License, which permits unrestricted use, distribution, and reproduction in any medium, provided the original work is properly cited.

\begin{abstract}
The polynuclear complexes $\left[\mathrm{Mo}_{3} \mathrm{O}_{8}(\mathrm{tidf})\right] \cdot \mathrm{dmso} \cdot 2 \mathrm{H}_{2} \mathrm{O}(\mathbf{1})$ and $\left[\left\{\mathrm{Cu}_{2}(\mathrm{tidf})\right\}_{2}\left(\mu-\mathrm{Mo}_{8} \mathrm{O}_{24}\right)\right](2)\left(\right.$ tidf ${ }^{2-}$ is a symmetrical tetraiminodiphenolate Robson-type macrocyclic ligand) were prepared from equimolar combinations of $\left[\mathrm{Mg}_{2}(\operatorname{tidf})\right]\left(\mathrm{NO}_{3}\right)_{2} \cdot 4 \mathrm{H}_{2} \mathrm{O}$, $\left[\mathrm{MoO}_{2} \mathrm{Cl}_{2}(\mathrm{dmso})_{2}\right]$ (for $\left.\mathbf{1}\right)$ and complex 1 and $\mathrm{Cu}\left(\mathrm{ClO}_{4}\right)_{2} \cdot 4 \mathrm{H}_{2} \mathrm{O}$ (for 2$)$ in acetonitrile. Molecular structures of both complexes were determined and showed atypical modes of coordination. A significant observation was the remarkable flexibility of the macrocycle ligand that effectively accommodated the steric demands of metal cations and the packing forces and showed a unique mode of coordination. Spectroscopic (UV-vis and FTIR) and redox properties are discussed.
\end{abstract}

\section{Introduction}

This work is related to the current interest in searching for multimetallic complexes based on symmetric macrocycles, especially heterometallic ones. Rational design and synthesis of such compounds are not trivial, particularly with labile first-row transition metal ions like copper(II) [1-6]. Self-assembly through metal-ligand interactions to prepare macrocyclic complexes with novel properties and structures has been used for years and continues to be a major subject in current coordination and synthetic inorganic chemistry [7$11]$.

Symmetrical tetraiminodiphenolate Robson-type macrocyclic ligands, obtained by condensation of 2,6-diformyl-4methylphenol and diamines, have been extensively investigated over the years and preparation usually is achieved by template and transmetallation reactions [12-14]. Conversely, their related heterodinuclear complexes appear in limited number in the literature [15-18].

Preparation of heteronuclear complexes can be difficult because labile metal ions may swap positions by an intramolecular mechanism and this metal scrambling leads to mixtures of products. Thermodynamics drives the process making it difficult to control metal ion composition at the molecular level.

The chemistry of molybdenum(VI) frequently is governed by the formation of polyoxoanions due to the combination of charge, radius, and vacant $d$-orbitals accessible for metal-oxygen bonding [19]. As a result of this Mo-O $\pi$ bonding, among the vast variety of compositions, a common structural feature of the polyoxometalates is that the metal ion is displaced towards the $\mathrm{MoO}_{x}$ polyhedral vertices forming the surface of the solid. An interesting property of polyoxometalates is that a whole range of metal-metal interactions is observed, from very strong to extremely weak. In each case, the cluster preserves the symmetry of its central oxygen polyhedron, which can be an octahedron, a tetrahedron, or an icosahedron $[19,20]$. Interesting chemical properties like size, shape, charge, good solubility in polar and nonpolar solvents, electron and proton-transfer capabilities, high Brönsted acidity, and thermal stability guarantee a broad range of applications for polyoxometalates, as given in excellent reviews [21-23].

Continuing our interest in the syntheses of metal complexes of the Robson family (Scheme 1) in this work we report 

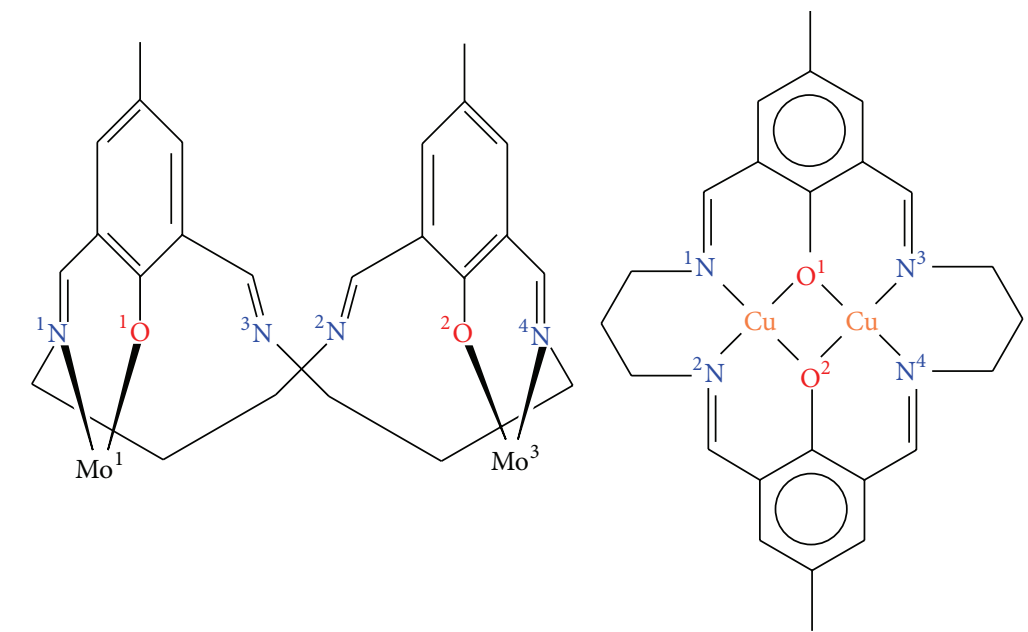

SCHeme 1: Modes of coordination of the ligand tidf ${ }^{2-}$. Numbering refers to Figures 2 and 3.

on the preparation, molecular structure, and spectroscopic properties of two original copper and polyoxomolybdate compounds.

\section{Materials and Methods}

Reagent grade chemicals were used in this work. The syntheses of $\left[\mathrm{MoO}_{2} \mathrm{Cl}_{2}(\mathrm{dmso})_{2}\right]\left[\mathrm{Mg}_{2}\right.$ (tidf) $]\left(\mathrm{NO}_{3}\right)_{2} \cdot 4 \mathrm{H}_{2} \mathrm{O}$ and $\left[\mathrm{Cu}_{2}\right.$ (tidf) $\left.\left(\mathrm{H}_{2} \mathrm{O}\right)_{2}\left(\mathrm{ClO}_{4}\right)_{2}\right]$ are done according to published procedures $[24,25]$.

2.1. Syntheses. $\left[\mathrm{Mo}_{3} \mathrm{O}_{8}(\mathrm{tidf})\right] \cdot \mathrm{dmso} \cdot 2 \mathrm{H}_{2} \mathrm{O}(\mathbf{1})$ is as follows. $\left[\mathrm{Mg}_{2}\right.$ (tidf) $]\left(\mathrm{NO}_{3}\right)_{2} \cdot 4 \mathrm{H}_{2} \mathrm{O}(0.65 \mathrm{~g}, 1.0 \mathrm{mmol})$ was dissolved in $60 \mathrm{~mL}$ of acetonitrile at $75^{\circ} \mathrm{C}$ and mixed with $0.36 \mathrm{~g}$ $(1.0 \mathrm{mmol})$ of $\left[\mathrm{MoO}_{2} \mathrm{Cl}_{2}(\mathrm{dmso})_{2}\right]$ and $0.55 \mathrm{~g}(4 \mathrm{mmol})$ of $\mathrm{NaClO}_{4}$ dissolved in $20 \mathrm{~mL}$ of acetonitrile. A rapid color change from yellow to orange was observed along with immediate precipitation. The system was kept under reflux for $2 \mathrm{~h}$ and later the reaction volume was reduced to $40 \mathrm{~mL}$ under vacuum. After that, the reaction mixture was kept at $-15^{\circ} \mathrm{C}$ for $1 \mathrm{~h}$. An orange powder was filtrated off and washed with acetonitrile and diethyl ether and dried under vacuum. The yield was $0.47 \mathrm{~g}(58 \%)$ (elemental analysis calculated for $\mathrm{C}_{26} \mathrm{H}_{34} \mathrm{Mo}_{3} \mathrm{~N}_{4} \mathrm{O}_{12} \mathrm{~S}$ C, 34.15; H, 3.75; N, 6.13\%. Found: C, $36.12 ; \mathrm{H}, 4.15 ; \mathrm{N}, 7.02 \%)$.

$\left[\left\{\mathrm{Cu}_{2}(\mathrm{tidf})\right\}_{2}\left(\mu-\mathrm{Mo}_{8} \mathrm{O}_{24}\right)\right]$ (2) is as follows. Complex $\mathbf{1}$ $(0.40 \mathrm{~g}, 0.50 \mathrm{mmol})$ was suspended in $50 \mathrm{~mL}$ of acetonitrile at $75^{\circ} \mathrm{C}$ and mixed with a solution of $0.17 \mathrm{~g}(0.50 \mathrm{mmol})$ of $\mathrm{Cu}\left(\mathrm{ClO}_{4}\right)_{2} \cdot 4 \mathrm{H}_{2} \mathrm{O}$ in $10 \mathrm{~mL}$ of acetonitrile. The reaction mixture was kept under reflux for $24 \mathrm{~h}$, during which the color changed from orange to olive-green. A green solid was isolated by centrifugation, washed several times with acetonitrile and ether, and dried under vacuum. The yield was $0.21 \mathrm{~g}\left(53 \%\right.$ ) (elemental analysis calculated for $\mathrm{C}_{48} \mathrm{H}_{52} \mathrm{Cu}_{4}$ $\mathrm{Mo}_{8} \mathrm{~N}_{8} \mathrm{O}_{28}$ (2210.67 $\mathrm{g} \mathrm{mol}^{-1}$ ): C, 26.08; H, 2.37; N, 5.07\%. Found: C, 26.29; H, 2.82; N, 5.55\%).

2.2. Instruments. Bruker D8 VENTURE PHOTON 100 diffractometer operated using graphite monochromator and
Mo-K $\alpha$ radiation $(\lambda=0.71073 \AA$ ) was used for the X-ray structure analyses. The crystal structure was solved by direct methods with SHELXT2015 [26]. The final structure was refined with SHELXL2013 [26] with anisotropic displacement parameters for all nonhydrogen atoms; hydrogen atoms were refined isotropically as riding atoms at their theoretical ideal positions [27]. Drawings were made with Olex2 [28]. For compound 2, disordered solvent dmso molecules were observed and modeled properly. The dmso molecules were refined with split atomic positions of the molecule over two positions.

Infrared spectra were obtained with a FTS3500GX BioRad Excalibur series spectrophotometer in the region 4000$400 \mathrm{~cm}^{-1}$ in $\mathrm{KBr}$ pellets.

UV-visible spectra in the range $190-900 \mathrm{~nm}$ were obtained on VARIAN Cary 100 spectrophotometer in the solid state by diffuse reflectance with a Labsphere integration sphere.

Cyclic voltammetry was carried out with IVIUM CompactStat potentiostat/galvanostat. A platinum disc electrode was employed for the measurements at $\mathrm{I}=0.1 \mathrm{~mol} \mathrm{~L}^{-1} \mathrm{kept}$ constant with $\mathrm{TBAPF}_{6}$ (tetrabutylammonium hexafluorophosphate). A silver wire along with a platinum wire was used as semireference and auxiliary electrodes, respectively. Potentials are reported against ferrocenium/ferrocene $(+0.400 \mathrm{~V}$ versus $\mathrm{SHE}$ ) used as an internal reference. Typical experiments were conducted with a $3.0 \times 10^{-3} \mathrm{~mol} \mathrm{~L}^{-1}$ complex concentration in dimethylsulfoxide solutions at ambient temperature.

Microanalyses were performed with a Perkin Elmer CHN 2400 equipment.

\section{Results and Discussion}

3.1. Syntheses. We started this project in an attempt to find a route to the synthesis of heterometallic macrocyclic complexes using our previous knowledge about the coordination chemistry of the tetraiminodiphenolate macrocyclic ligand, 


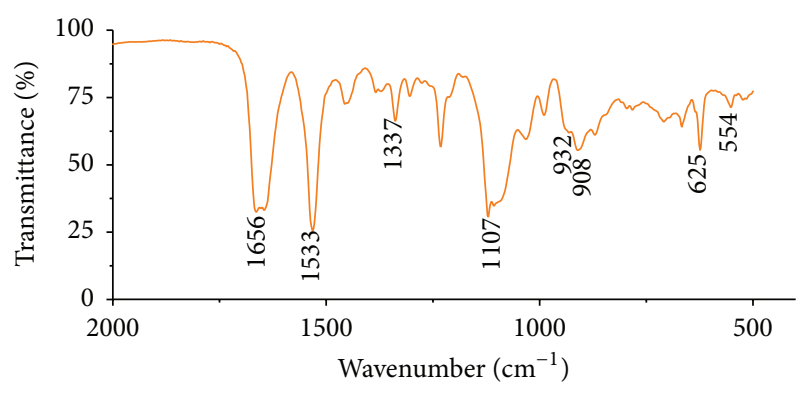

- Complex 1

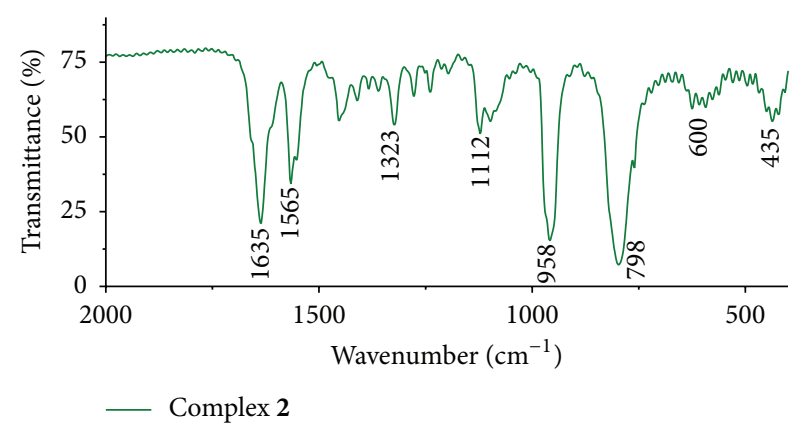

FIGURE 1: Infrared spectrum of complexes $\mathbf{1}$ and $\mathbf{2}$ in $\mathrm{KBr}$.

tidf $^{2-}$. It is well known that transmetalation reactions favor the formation of homometallic compounds, especially with symmetric ligands in the presence of labile first-row transition metal ions $[1,28-32]$. We expected that the inertia of a second row and high charge transition metal ion such as $\mathrm{Mo}^{6+}$ ion would be useful to design a rational method for the preparation of heterodinuclear complexes of the Robsontype family in nonaqueous media. Most of the polyoxometalates described in the literature were formed and studied in aqueous solution [22]. Thus, compounds $\mathbf{1}$ and 2 herein described were not anticipated and we predicted different products, explicitly the mononuclear $\left[\mathrm{MoO}_{2}\right.$ (tidf$\left.\left.\mathrm{H}_{2}\right)\left(\mathrm{ClO}_{4}\right)_{2}\right]$ and heterodinuclear $\left[\mathrm{CuMoO}_{2}(\mathrm{tidf})\left(\mathrm{ClO}_{4}\right)_{2}\right]$ complexes. The elevated stability of the polyoxomolybdate anion together with the high lability and equally high thermodynamic affinity of copper(II) for the tidf ${ }^{2-}$ ligand created a different outcome for the synthesis.

3.2. Infrared Spectra. Figure 1 shows the infrared spectra of complexes 1 and 2. The bands (ones in parenthesis are for complex 2) at 1337 (1323), 1533 (1565), and $1656(1635) \mathrm{cm}^{-1}$ are characteristic of the macrocyclic ligand $\mathrm{tidf}^{2-}$ and assigned as $v(\mathrm{C}-\mathrm{O}), v(\mathrm{C}=\mathrm{C})$, and $\nu(\mathrm{C}=\mathrm{N})$ modes, respectively $[1,33]$. Both complexes exhibited bands due to the symmetric and antisymmetric stretchings $\nu(\mathrm{Mo}=\mathrm{O})$ at $932(958)$ and 908 (798) $\mathrm{cm}^{-1}$ in that order $[34,35]$. Values seen for the parent complex $\left[\mathrm{MoO}_{2} \mathrm{Cl}_{2}(\mathrm{dmso})_{2}\right]$ appear at 918 and $889 \mathrm{~cm}^{-1}$ [34]. Bands at $1107(1112) \mathrm{cm}^{-1}$ for complexes 1 and 2 were assigned to the $\mathrm{S}=\mathrm{O}$ stretching, similar to other sulfoxides complexes $[34,35]$. In addition, weak bands shown around 600 (625) and $554(435) \mathrm{cm}^{-1}$ observed in complex 2 were attributed to metal-nitrogen and metal-oxygen stretchings, respectively. Oxygen atoms acting as bridges between two or more metal ions increase the reduced mass of the vibrating fragment, thus decreasing the vibration frequency. Since complex 2 has several different metal-oxygen vibration modes close in energy, this region of the spectrum concentrates a large number of weak bands.

3.3. Crystal Structures. Suitable crystals of complexes 1 and 2 for X-ray diffraction were obtained after slow evaporation of dimethylsulfoxide solutions. Figures 2 and 3 show the molecular representation of complexes 1 and 2 . Table $1 S$ (in Supplementary Material available online at http://dx.doi.org/ $10.1155 / 2015 / 506932$ ) presents detailed information about the structure determinations and Table 1 shows selected bond distances and angles. Full crystallographic data for complexes $\mathbf{1}$ and $\mathbf{2}$ were deposited in Cambridge Crystallographic Data Centre under the following numbers CCDC 1050597 and 1051415.

Complex 1 crystallized in the monoclinic system, $P 2_{1} / n$ space group, and the asymmetric unit contains two crystallographically independent trinuclear molecules. Its molecular structure shows a singular mode of coordination of the macrocycle ligand tidf $^{2-}$, never seen before. The macrocycle is very much folded and binds two molybdenum cations via one nitrogen and one phenolate oxygen atoms. These two molybdenum ions complete their coordination sphere through bonding to four oxygen atoms, two terminals and two bridges (one $\mu_{2}$ - and one $\mu_{3}-$ ) that connect them to a third metal ion, which is not bound to the macrocyclic ligand. This molybdenum ion is pentacoordinated in a distorted trigonal bipyramidal geometry, bonded to two terminal oxygen atoms and attached to the other metal cations through two $\mu_{2}$ and one $\mu_{3}$-oxygen bridges. This trinuclear cluster shows a metal-metal bond distance of $3.108 \AA$. Dutta and coworkers observed a folded configuration of the $\operatorname{tidf}^{2-}$ ligand in the lead complex $\left[\mathrm{Pb}\left(\mathrm{H}_{2} \text { tidf }\right)\right]^{2+}$ with a dihedral angle between the two phenyl rings as low as $69.3(5)^{\circ}$ [36]. In that case, however, the mode of coordination of the macrocycle is different than the one observed in here, with two imine $N$ and two phenolate $O$ bonding instances to a single metal ion.

Polyoxometalate anions can act as ligands and bind metal cations via terminal and bridging oxygen atoms. For instance, the heteropolymetalate $\left[\left(\mathrm{V}^{\mathrm{V}} \mathrm{Mo}_{8} \mathrm{~V}_{4}{ }^{\mathrm{IV}} \mathrm{O}_{40}\right)\left(\mathrm{V}^{\mathrm{IV}} \mathrm{O}_{4}\right)_{2}\right]^{7-}$ subunit acts as a monodentate ligand and links two $\mathrm{Ni}^{\mathrm{II}}$ ions through a terminal oxygen bridge [37], while a polyanion can also form dimeric moieties such as $\left[\left(\mathrm{Cp}^{*} \mathrm{TiW}_{5} \mathrm{O}_{18}\right)_{2} \mathrm{Ru}_{2}(\mathrm{CO})_{4}\right]^{4-}$, in which the ruthenium(I) ions are coordinated to three oxygen atoms of the polyanion [38].

Complex 2 crystallized as the neutral solvate $\left[\left\{\mathrm{Cu}_{2}(\mathrm{tidf})\right\}_{2}\left(\mathrm{Mo}_{8} \mathrm{O}_{24}\right)\right] \cdot 12 \mathrm{dmso}$ in the monoclinic system and $C 2 / c$ space group. It contains two units of $\left[\mathrm{Cu}_{2}(\mathrm{tidf})\right]^{2+}$ in which the copper ions are bound to a phenolate oxygen and iminic nitrogen atoms of the macrocyclic ligand, tidf $^{2-}$. Those units are bridged through four terminal oxygen donors of the polyoxomolybdate $\left[\mathrm{Mo}_{8} \mathrm{O}_{24}\right]^{4-}$ anion in a bis(bidentate) fashion, simultaneously coordinating to all four copper centers, while the macrocycle ligand tidf $^{2-}$ adopts a saddle 


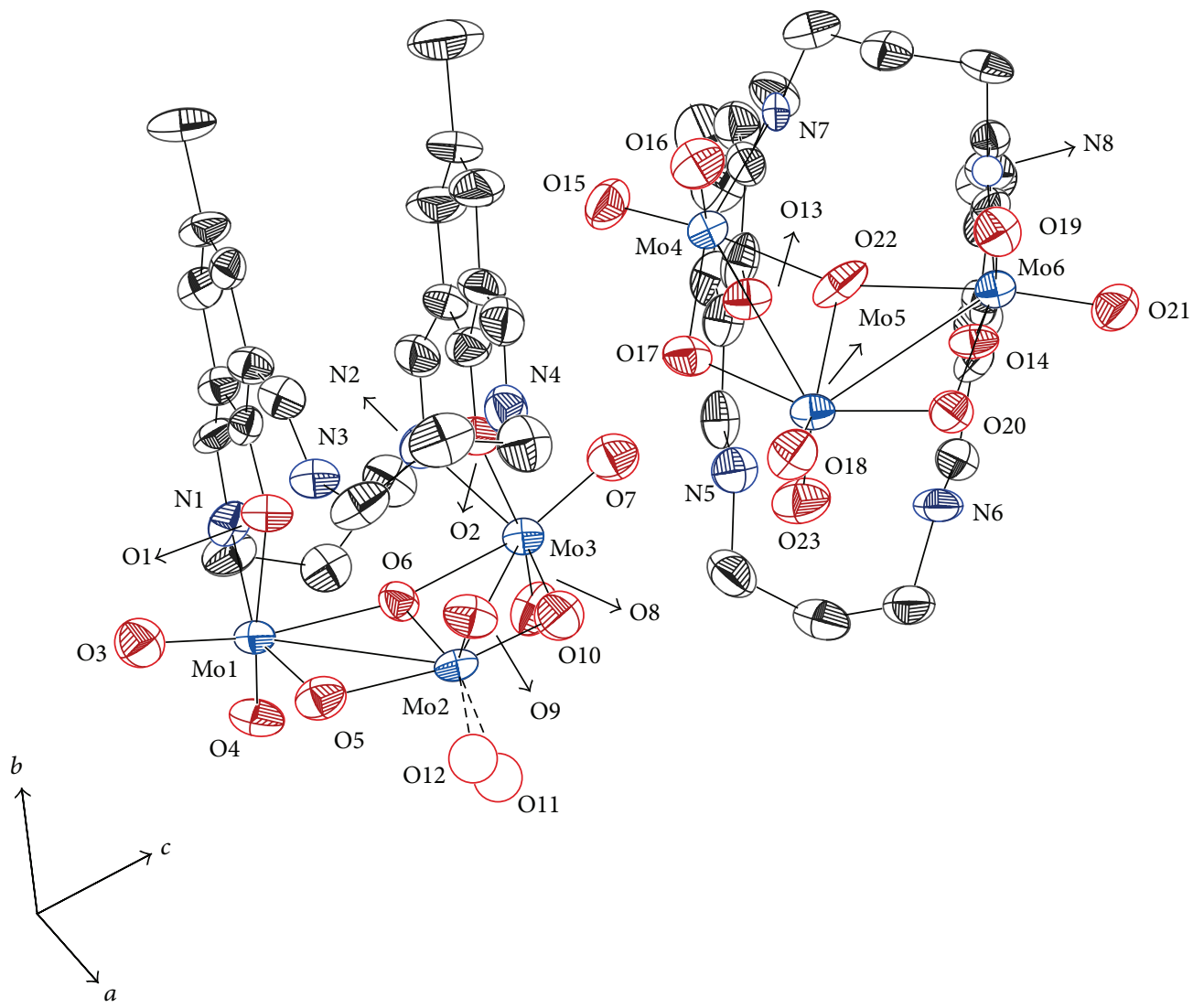

(a)

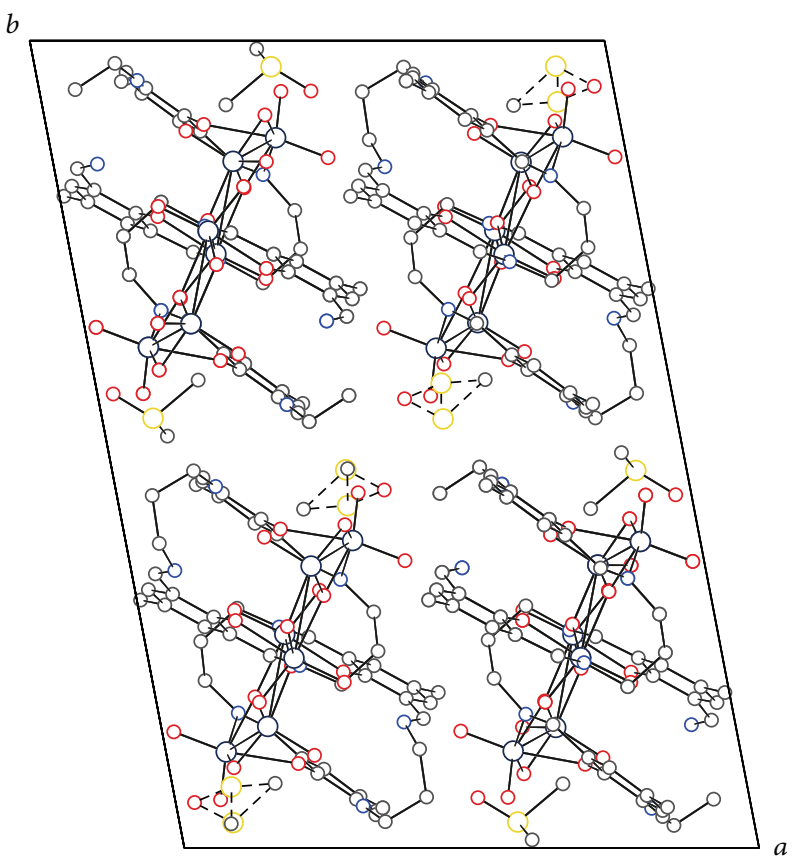

(b)

FIGURE 2: Molecular structure with the atom-labeling scheme. (a) Ellipsoids of the asymmetric unit drawn at 50\% probability level. The dmso and the hydrogen atoms were omitted for sake of clarity. (b) Packing of complex 1 along the $b$-axis the hydrogen atoms were omitted for sake of clarity. 


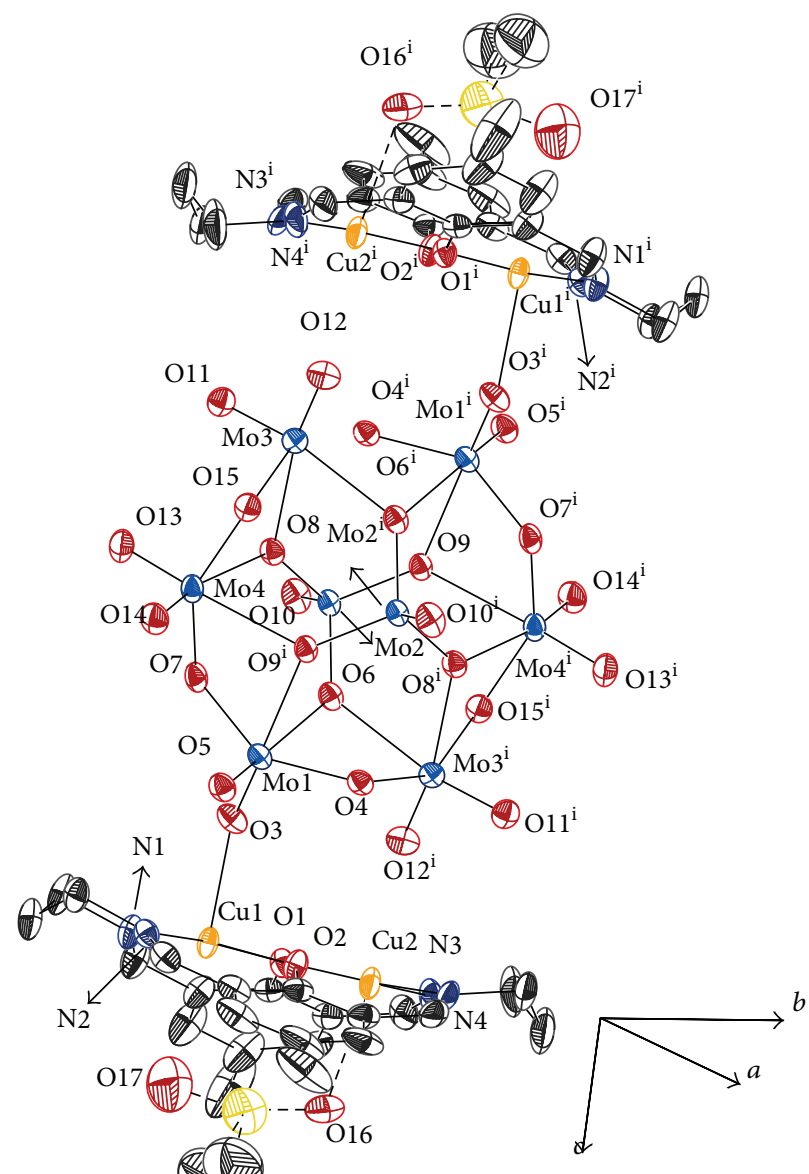

(a)

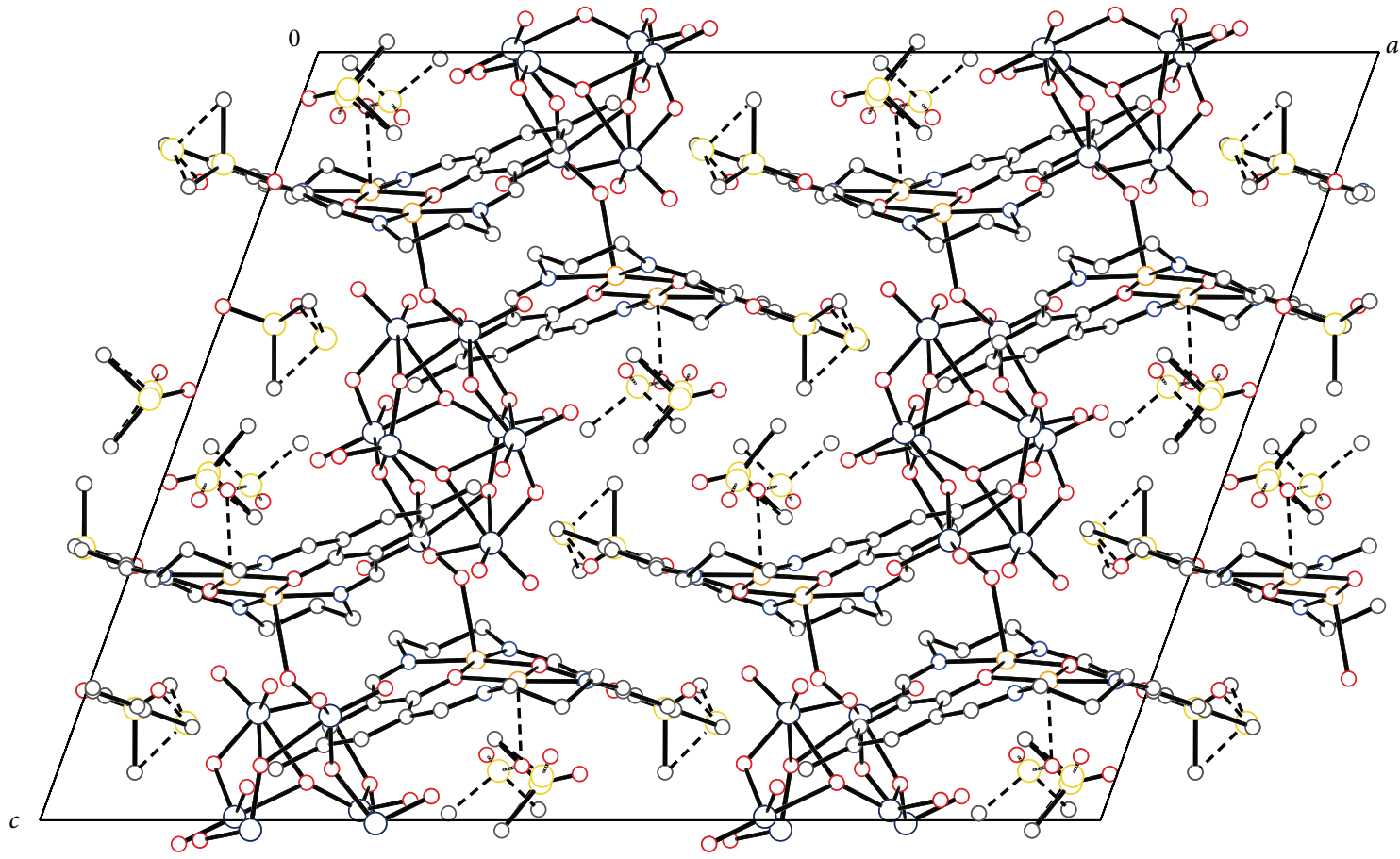

(b)

Figure 3: (a) Molecular structure with the atom-labeling scheme. Ellipsoids are drawn at $50 \%$ probability level. The dmso and the hydrogen atoms were omitted for sake of clarity. (b) Packing of complex 2 along the $b$-axis the hydrogen atoms were omitted for sake of clarity. 
TABLE 1: Selected bond lengths/Å and angles/ for complexes $\mathbf{1}$ and $\mathbf{2}$.

\begin{tabular}{|c|c|c|c|}
\hline \multicolumn{2}{|c|}{ Complex 1} & \multicolumn{2}{|c|}{ Complex 2} \\
\hline Mol-O1 $1_{\text {phenolate }}$ & $2.204(9)$ & Cul-N1 & $1.953(5)$ \\
\hline Mol-O3 ${ }_{\text {terminal }}$ & $1.711(12)$ & Cul-O1 $1_{\text {phenolate }}$ & $1.969(4)$ \\
\hline Mo1-O5 ${ }_{\text {bridge }(\mu 2)}$ & $1.883(10)$ & Cul-O3 $3_{\text {molibdate }}$ & $2.316(4)$ \\
\hline Mo1-O6 $6_{\text {bridge }(\mu 3)}$ & $2.142(10)$ & $\mathrm{Cu2}-\mathrm{O} 16_{\mathrm{dmso}}$ & $2.435(5)$ \\
\hline Mo1-N1 & $2.230(10)$ & Mo2-O10 terminal & $1.712(4)$ \\
\hline Mo1-Mo2 & $3.1466(17)$ & Mo2-O6 $6_{\text {bridge }(\mu 2)}$ & $1.781(4)$ \\
\hline Mo2-Mo3 & $3.1099(15)$ & Mo2-O $8_{\text {bridge }(\mu 3)}$ & $1.790(4)$ \\
\hline Mo2-O5 $5_{\text {bridge }(\mu 2)}$ & $1.988(11)$ & Mol-O3 ${ }_{\text {bridge with }} \mathrm{Cu}$ & $1.709(4)$ \\
\hline Mo2-O6 $6_{\text {bridge }(\mu 3)}$ & $2.000(9)$ & N1-Cu1-N2 & $97.5(2)$ \\
\hline Mo2-O9 $9_{\text {terminal }}$ & $1.710(9)$ & $\mathrm{O} 1_{\text {phenolate }}-\mathrm{Cul}-\mathrm{O} 2_{\text {phenolate }}$ & $77.49(17)$ \\
\hline Mo1-Mo2-Mo3 & $84.90(4)$ & $\mathrm{O} 16_{\mathrm{dmso}}-\mathrm{Cu} 2-\mathrm{O} 1_{\text {phenolate }}$ & $83.69(17)$ \\
\hline Mo1-O5-Mo2 & $108.7(5)$ & $\mathrm{O} 1_{\text {phenolate }}-\mathrm{Cu}-\mathrm{N} 1$ & $92.1(2)$ \\
\hline Mo1-O6-Mo2 & $98.8(4)$ & $\mathrm{O} 16_{\mathrm{dmso}}-\mathrm{Cu} 2-\mathrm{N} 3$ & $98.5(2)$ \\
\hline Mo1-O6-Mo3 & $162.9(5)$ & $\mathrm{O} 3_{\text {molibdate }}$-Cul-N1 & $96.5(2)$ \\
\hline $\mathrm{O} 3_{\text {terminal }}-\mathrm{Mol}-\mathrm{O} 1_{\text {phenolate }}$ & $86.6(5)$ & $\mathrm{Cul}-\mathrm{O} 3_{\text {molibdate }}-\mathrm{Mo1}$ & $140.9(2)$ \\
\hline $\mathrm{O} 3_{\text {terminal }}-$ Mol-O $4_{\text {terminal }}$ & $101.8(6)$ & O3-Mol-O4 & $101.8(2)$ \\
\hline $\mathrm{O} 3_{\text {terminal }}-\mathrm{Mol}-\mathrm{O} 5_{\text {bridge }(\mu 2)}$ & $103.9(5)$ & O3-Mo1-O5 & $104.6(2)$ \\
\hline $\mathrm{O} 3_{\text {terminal }}-\mathrm{Mol}-\mathrm{O} 6_{\text {bridge }(\mu 3)}$ & $166.7(5)$ & O3-Mo1-O6 & $87.53(18)$ \\
\hline
\end{tabular}

conformation due to the packing forces in the crystal. The species $\left[\mathrm{Mo}_{8} \mathrm{O}_{24}\right]^{4-}$ are mixed valence since the net charge (4-) of the anion can only be accounted if we consider the presence of two tetracoordinated $\mathrm{Mo}^{4+}$ and six hexacoordinated $\mathrm{Mo}^{6+}$ ions in the molecular composition. A logical alternative would be to consider the formation of a $\mathrm{Mo}_{4}{ }^{\mathrm{V}} \mathrm{Mo}_{4}{ }^{\mathrm{VI}}$ cluster instead of $\mathrm{Mo}_{2}{ }^{\mathrm{IV}} \mathrm{Mo}_{6}{ }^{\mathrm{VI}}$. It seems unlikely, though, because the $\mathrm{Mo}^{\mathrm{V}} \mathrm{Mo}^{\mathrm{VI}}$ unit, similarly to the tungstates, would exhibit a characteristic blue color due to intervalence charge transfer transitions and they have a tendency to undergo intramolecular disproportionation favoring the $\mathrm{Mo}^{\mathrm{IV}} \mathrm{Mo}^{\mathrm{VI}}$ species. The green color observed for complex $\mathbf{2}$ is due to a ligand field transition between the copper(II) $d$-orbitals, a behavior also observed in the dinuclear complex $\left[\mathrm{Cu}_{2}(\mathrm{tidf})\left(\mathrm{ClO}_{4}\right)_{2}\left(\mathrm{H}_{2} \mathrm{O}\right)_{2}\right][25,33]$.

Compound 2 has a $\mathrm{Mo}_{8} \mathrm{O}_{24}$ polyoxo unit, a cage of the known series $\left(\mathrm{Mo}_{2} \mathrm{O}_{6}\right)_{m}$ (where $m=4$ ), although not frequently reported, with observed bond lengths measured in this work at Mo-O $\mathrm{O}_{\text {terminal }}(1.712(4) \AA), \mathrm{Mo} \mathrm{O}_{\text {bridge with Mo }}$ (1.79 $\AA$ average value), Mo- $\mathrm{O}_{\text {bridge with } \mathrm{Cu}}(1.709(4) \AA)$, and Mo-Mo ( $3.51 \AA$, average value). Compare those with values reported in the literature [20] at 1.67-1.69 $\AA$ (for Mo$\left.\mathrm{O}_{\text {terminal }}\right), 1.85-1.97 \AA\left(\mathrm{Mo}^{-} \mathrm{O}_{\text {bridge with Mo }}\right)$, and $3.42-3.73 \AA$ (Mo-Mo bond distance range). The self-assembly of complex 2 was carried out from the reaction between complex $\mathbf{1}$ and the hydrated $\mathrm{Cu}\left(\mathrm{ClO}_{4}\right)_{2} \cdot 4 \mathrm{H}_{2} \mathrm{O}$ salt in acetonitrile, which is a solvent used as purchased and not dried. At this moment we do not have an unequivocal proof as to the nature of the reducing agent responsible for the reduction of $\mathrm{Mo}^{6+}$, but, considering that many of the polyoxometalates are indeed formed in aqueous solutions, the presence of water in the system most likely favored the $\mathrm{Mo}^{6+} \rightarrow \mathrm{Mo}^{4+}$ conversion.
Typical distorted octahedral and tetrahedral bond angles were seen for complex 2, such as O3-Mol-O7 $99.4^{\circ}$ and O10-Mo2-O9 $109.8^{\circ}$. The hexacoordination of each of the copper(II) ions is achieved through coordination to $\mathrm{O} 16$ and $\mathrm{O} 17$ from dmso molecules and experiences a typical tetragonal elongation of the axial bond lengths, evidenced by comparing $\mathrm{Cu} 2-\mathrm{O} 2$ (equatorial) and $\mathrm{Cu} 2-\mathrm{O} 16$ (axial-dmso) at $1.962(4) \AA$ and 2.436(5) $\AA$, respectively.

In general, bond distances and angles found here for the copper(II) molecule are comparable to those reported by Mandal et al. for $\left[\mathrm{Cu}_{2}(\mathrm{tidf})\left(\mathrm{ClO}_{4}\right)_{2}\left(\mathrm{H}_{2} \mathrm{O}\right)_{2}\right]$ [25] and by Samulewski et al. [33].

3.4. Electronic Spectroscopy. UV-vis spectra of complexes $\mathbf{1}$ and 2 are similar as seen in Figure 4. The main spectral features are a $\left(\pi \rightarrow \pi^{*}\right)$ phenolate band at $264 \mathrm{~nm}(\varepsilon=6.1 \times$ $\left.10^{4} \mathrm{~L} \mathrm{~mol}^{-1} \mathrm{~cm}^{-1}\right)$ and $\left(\pi \rightarrow \pi^{*}\right)_{\text {imine }}$ bands $(\varepsilon \sim 1.3 \times$ $\left.10^{4} \mathrm{~L} \mathrm{~mol}^{-1} \mathrm{~cm}^{-1}\right)$ in the $330-450 \mathrm{~nm}$ range. Complex 2 shows a broad ligand field transition of the copper(II) ion centered at $621 \mathrm{~nm}\left(\varepsilon=99 \mathrm{~L} \mathrm{~mol}^{-1} \mathrm{~cm}^{-1}\right)$. Also, a very discreet shoulder can be seen (e.g., in complex 1) around 450$500 \mathrm{~nm}$ and it was attributed to a ligand-to-metal charge transfer transition.

3.5. Electrochemical Properties. Complex 1 showed an irreversible monoelectronic reduction $\mathrm{Mo}^{6+} \rightarrow \mathrm{Mo}^{5+}$ at $E_{\mathrm{pc}}=$ $-1.39 \mathrm{~V}$ versus $\mathrm{Fc}^{+} / \mathrm{Fc}$ as seen in Figure 5. The irreversible wave observed $-2.17 \mathrm{~V}$ is most likely due to the reduction of the macrocyclic ligand $\operatorname{tidf}^{2-}$, since the magnesium complex $\left[\mathrm{Mg}_{2}(\mathrm{tidf})_{2}(\mathrm{dmso})_{2}\right]^{2+}$ undergoes irreversible reductions between -1.58 and $-2.35 \mathrm{~V}$ versus $\mathrm{Fc}^{+} / \mathrm{Fc}$ and the magnesium ion is not electroactive in that range of potential. 

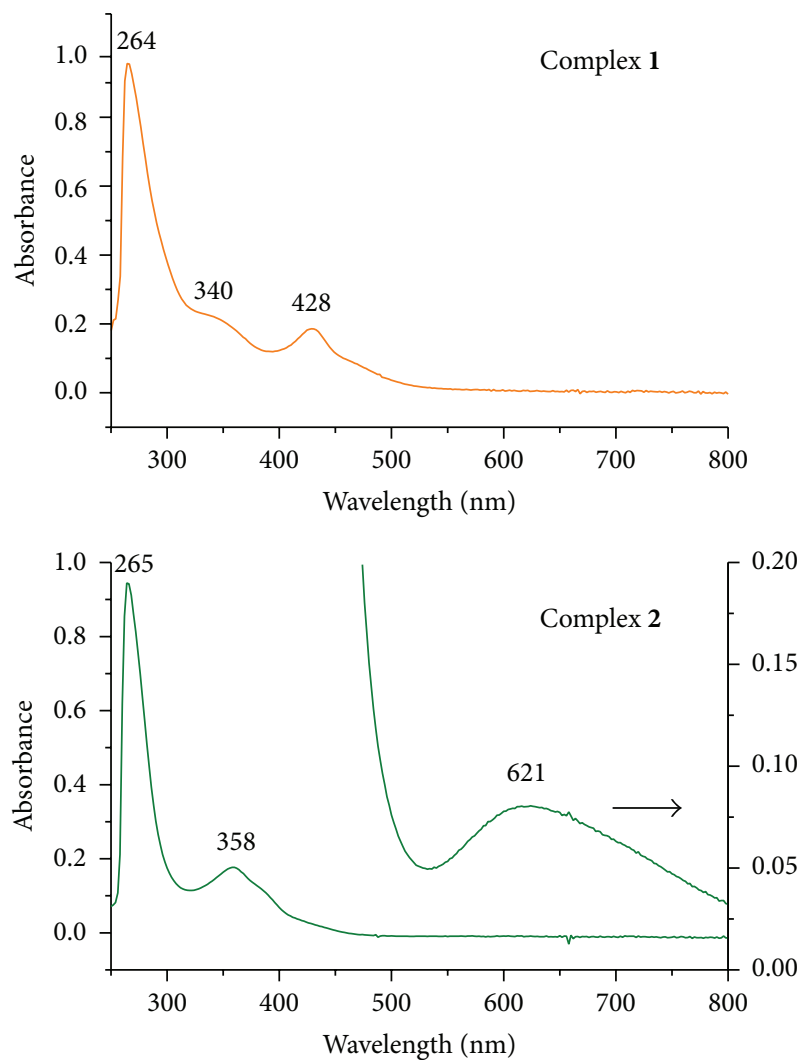

FIGURE 4: Electronic spectrum of complexes $\mathbf{1}$ and $\mathbf{2}$ in dimethylsulfoxide.
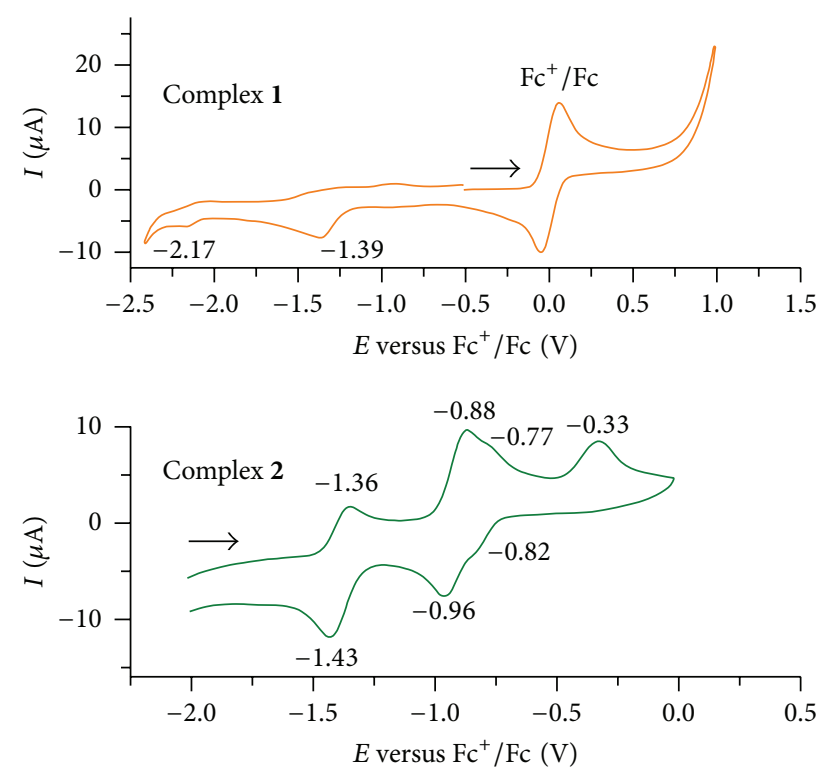

FIGURE 5: Cyclic voltammetry of complexes $\mathbf{1}$ and $\mathbf{2}$ in dimethylsulfoxide.

On the other hand cyclic voltammograms of $\mathbf{2}$ in dimethylsulfoxide exhibited a complex overlaid pattern of waves as seen in Figure 5. The two pairs of reversible waves at $E_{1 / 2}$ $=-1.40$ and $-0.92 \mathrm{~V}$ versus $\mathrm{Fc}^{+} / \mathrm{Fc}$ are due to $\mathrm{Cu}^{\mathrm{I}} / \mathrm{Cu}^{\mathrm{I}} \leftrightarrow$ $\mathrm{Cu}^{\mathrm{II}} / \mathrm{Cu}^{\mathrm{I}}$ and $\mathrm{Cu}^{\mathrm{II}} / \mathrm{Cu}^{\mathrm{I}} \leftrightarrow \mathrm{Cu}^{\mathrm{II}} / \mathrm{Cu}^{\mathrm{II}}$ couples as seen in the parent complex $\left[\mathrm{Cu}_{2}(\mathrm{tidf})_{2}\left(\mathrm{ClO}_{4}\right)_{2}\right]^{2+}[25]$. The voltammograms also show one more reversible process just adjacent to the copper waves and slightly shifted to the anodic side of the potential range at $E_{1 / 2}=-0.80 \mathrm{~V}$. This process was assigned to the one-electron $\mathrm{Mo}^{4+} \leftrightarrow \mathrm{Mo}^{5+}$ oxidation. Lastly, the wave at $E_{\mathrm{pa}}=-0.33 \mathrm{~V}$ was attributed to the irreversible $\mathrm{Mo}^{5+} \rightarrow \mathrm{Mo}^{6+}$ oxidation.

\section{Conclusion}

Although polyoxomolybdates are known for many decades, their ability to act as ligands to metal cations continues to be revealed and new structural features emerge.

Complex 1 was surprisingly obtained when $\left[\mathrm{Mg}_{2}\right.$ (tidf) $]\left(\mathrm{NO}_{3}\right)_{2} \cdot 4 \mathrm{H}_{2} \mathrm{O}$ reacted with $\left[\mathrm{MoO}_{2} \mathrm{Cl}_{2}(\mathrm{dmso})_{2}\right]$ in a 1:1 molar ratio in acetonitrile solutions. The complex illustrates the unique flexibility of the macrocycle ligand tidf $^{2-}$, which is severely bent.

In an attempt to prepare a heteronuclear macrocyclic compound, complex 1 was mixed with $\mathrm{Cu}\left(\mathrm{ClO}_{4}\right)_{2} \cdot 4 \mathrm{H}_{2} \mathrm{O}$ in acetonitrile and surprisingly the decanuclear $\left[\left\{\mathrm{Cu}_{2}(\mathrm{tidf})\right\}_{2}(\mu-\right.$ $\left.\mathrm{Mo}_{8} \mathrm{O}_{24}\right)$ ] (2) was isolated. Single crystal X-ray diffraction of $\mathbf{2}$ showed a discrete molecule in which two dicopper units $\left[\mathrm{Cu}_{2}(\mathrm{tidf})\right]^{2+}$ are connected through a polyoxomolybdate species. In this molecular structure the macrocycle ligand tidf ${ }^{2-}$ adopts a saddle conformation. For comparison, the mononuclear compound $\left[\mathrm{Fe}\right.$ (tidf) $\left.\left(\mathrm{CH}_{3} \mathrm{OH}\right)_{2}\right]\left(\mathrm{NO}_{3}\right)_{2}$ shows a curved macrocycle while in the dinuclear complex $\left[\mathrm{Fe}_{2}\right.$ (tidf) $\left.\left(\mathrm{CH}_{3} \mathrm{OH}\right)_{4}\right]\left(\mathrm{ClO}_{4}\right)_{2}$ the tidf ${ }^{2-}$ ligand is nearly a perfect plane.

From a practical perspective our results showed that the elevated thermodynamic stability of the polyoxomolybdate species frustrated our attempt to control the rational design of heteronuclear macrocyclic complexes. On the other hand, these results expanded our understanding of the coordination chemistry of this multifunctional and exceptionally flexible macrocyclic ligand, tidf ${ }^{2-}$, as they revealed its great bonding capacity to fit the steric demands of diverse metal ions.

Following our interest in the preparation of heterometallic compounds based on macrocycle chemistry, we are now conducting chemical modifications on the tetraiminodiphenolate macrocyclic ligand $\operatorname{tidf}^{2-}$, by adding fluorophore groups to it, and exploring the luminescence properties of its coordination compounds in an attempt to prepare new selective chemical sensors for transition metal ions.

\section{Conflict of Interests}

The authors declare that there is no conflict of interests regarding the publication of this paper.

\section{Acknowledgment}

The authors thank $\mathrm{CNPq}$ for research funds and fellowships.

\section{References}

[1] J. C. da Rocha, P. J. Zambiazi, M. Hörner, G. Poneti, R. R. Ribeiro, and F. S. Nunes, "Crystallographic evidence of metal 
scrambling in an $\mathrm{N}_{4} \mathrm{O}_{2}$-tetraiminodiphenolate macrocyclic complex," Journal of Molecular Structure, vol. 1072, no. 1, pp. 6976, 2014.

[2] J. L. Heinrich, P. A. Berseth, and J. R. Long, "Molecular Prussian Blue analogues: synthesis and structure of cubic $\mathrm{Cr}_{4} \mathrm{Co}_{4}(\mathrm{CN})_{12}$ and $\mathrm{Co}_{8}(\mathrm{CN})_{12}$ clusters," Chemical Communications, no. 11, pp. 1231-1232, 1998.

[3] R. Hernandez-Molina, V. P. Fedin, M. N. Sokolov, D. M. Saysell, and A. G. Sykes, "Preparation and properties of group 13 (Ga, In, $\mathrm{Tl}$ ) heterometallic single and corner-shared double cube derivatives of $\left[\mathrm{Mo}_{3} \mathrm{~S}_{4}\left(\mathrm{H}_{2} \mathrm{O}\right)_{9}\right]^{4+}$ and related studies," Inorganic Chemistry, vol. 37, no. 17, pp. 4328-4334, 1998.

[4] R. Hernandez-Molina, M. N. Sokolov, and A. G. Sykes, "Behavioral patterns of heterometallic cuboidal derivatives of $\left[\mathrm{M}_{3} \mathrm{Q}_{4}\left(\mathrm{H}_{2} \mathrm{O}\right)_{9}\right]^{4+}(\mathrm{M}=\mathrm{Mo}, \mathrm{W} ; \mathrm{Q}=\mathrm{S}, \mathrm{Se})$," Accounts of Chemical Research, vol. 34, no. 3, pp. 223-230, 2001.

[5] I. J. MacLean, R. Hernandez-Molina, M. N. Sokolov et al., "Preparation, structure and properties of three $\left[\mathrm{Mo}_{x} \mathrm{~W}_{4} \mathrm{~S}_{4}\left(\mathrm{H}_{2} \mathrm{O}\right)_{12}\right]^{5+}(x=1-3)$ and $\left[\mathrm{MoW}_{3} \mathrm{Se}_{4}\left(\mathrm{H}_{2} \mathrm{O}\right)_{12}\right]^{5+} \mathrm{cu}-$ boidal complexes alongside $\left[\mathrm{Mo}_{4} \mathrm{~S}_{4}\left(\mathrm{H}_{2} \mathrm{O}\right)_{12}\right]^{5+}$ and $\left[\mathrm{Mo}_{4} \mathrm{Se}_{4}\left(\mathrm{H}_{2} \mathrm{O}\right)_{12}\right]^{5+}$," Journal of Chemical Society Dalton Transations, no. 15, pp. 2557-2562, 1998.

[6] J. Zhou, J. W. Raebiger, C. A. Crawford, and R. H. Holm, "Metal ion incorporation reactions of the cluster $\left[\mathrm{Fe}_{3} \mathrm{~S}_{4}\left(\mathrm{LS}_{3}\right)^{3-}\right.$ containing the cuboidal $\left[\mathrm{Fe}_{3} \mathrm{~S}_{4}\right]^{0}$ core," Journal of the American Chemical Society, vol. 119, no. 27, pp. 6242-6250, 1997.

[7] M. D. Ward and P. R. Raithby, "Functional behaviour from controlled self-assembly: challenges and prospects," Chemical Society Reviews, vol. 42, no. 4, pp. 1619-1636, 2013.

[8] P. A. Vigato, S. Tamburini, and L. Bertolo, “The development of compartmental macrocyclic Schiff bases and related polyamine derivatives," Coordination Chemistry Reviews, vol. 251, no. 11-12, pp. 1311-1492, 2007.

[9] W. Huang, H.-B. Zhu, and S.-H. Gou, "Self-assembly directed by dinuclear zinc(II) macrocyclic species," Coordination Chemistry Reviews, vol. 250, no. 3-4, pp. 414-423, 2006.

[10] W. Radecka-Paryzek, V. Patroniak, and J. Lisowski, "Metal complexes of polyaza and polyoxaaza Schiff base macrocycles," Coordination Chemistry Reviews, vol. 249, no. 21-22, pp. 21562175, 2005.

[11] A. McAuley and S. Subramanian, "Formation of multinuclear complexes: new developments from cyclam derivatives," Coordination Chemistry Reviews, vol. 200-202, pp. 75-103, 2000.

[12] Q. R. Cheng, H. Zhou, Z. Q. Pan, G. Y. Liao, and Z. G. Xu, "Synthesis, crystal structure and magnetic properties of onedimensional coordination polymers," Polyhedron, vol. 81, pp. 668-674, 2014.

[13] A. Jana and S. Mohanta, "Syntheses, crystal structures, magnetochemistry and electrochemistry of macrocyclic dicopper(II) complexes: monodentate behavior of a potentially chelating ligand," Inorganica Chimica Acta, vol. 405, pp. 265-273, 2013.

[14] A. Jana, N. Aliaga-Alcalde, E. Ruiz, and S. Mohanta, "Structures, magnetochemistry, spectroscopy, theoretical study, and catechol oxidase activity of dinuclear and dimer-of-dinuclear mixed-valence $\mathrm{Mn}^{\mathrm{III}} \mathrm{Mn}^{\mathrm{II}}$ complexes derived from a macrocyclic ligand," Inorganic Chemistry, vol. 52, no. 13, pp. 77327746, 2013.

[15] R. R. Gagné, C. L. Spiro, T. J. Smith, C. A. Hamann, W. R. Thies, and A. K. Shiemke, "The synthesis, redox properties, and ligand binding of heterobinuclear transition-metal macrocyclic ligand complexes. Measurement of an apparent delocalization energy in a mixed-valent copper(I)copper(II) complex," Journal of the American Chemical Society, vol. 103, no. 14, pp. 4073-4081, 1981.

[16] S. Ohtsuka, M. Kodera, K. Motoda, M. Ohba, and H. Okawa, "Dinuclear $\mathrm{Cu}^{\mathrm{II}} \mathrm{M}^{\mathrm{II}}(\mathrm{M}=\mathrm{Co}, \mathrm{Ni}, \mathrm{Cu}$ or $\mathrm{Zn})$ and $\mathrm{Cu}^{\mathrm{II}} \mathrm{Cu}^{\mathrm{I}}$ complexes of a phenol-based dinucleating macrocycle with dissimilar $\mathrm{N}_{2} \mathrm{O}_{2}$ and $\mathrm{N}_{2} \mathrm{O}_{2} \mathrm{~S}$ sites," Journal of Chemical Society, Dalton Transactions, no. 16, pp. 2599-2604, 1995.

[17] T. Aono, H. Wada, Y. Aratake, N. Matsumoto, H. Okawa, and Y. Matsuda, "Crystal structure and spin-doublet electron spin resonance of a magnetically coupled di( $\mu$-phenoxo)-copper(II)nickel(II) complex," Journal of the Chemical Society, Dalton Transactions, no. 1, pp. 25-29, 1996.

[18] S. Mohanta, K. N. Nanda, L. K. Thompson, U. Florke, and K. Nag, "Spin exchange coupling in heterobimetallic M(II)V(IV)O $(\mathrm{M}=\mathrm{Cu}, \mathrm{Ni}, \mathrm{Co}, \mathrm{Fe}, \mathrm{Mn})$ macrocyclic complexes. Synthesis, structure, and properties," Inorganic Chemistry, vol. 37, no. 7, pp. 1465-1472, 1998.

[19] M. T. Pope and A. Müller, "Polyoxometalate chemistry: an old field with new dimensions in several disciplines," Angewandt Chemie-International Edition, vol. 30, no. 1, pp. 34-48, 1991.

[20] F.-Q. Zhang, H.-S. Wu, Y.-Y. Xu, Y.-W. Li, and H. Jiao, "Structure and stability of neutral polyoxometalate cages: $\left(\mathrm{Mo}_{2} \mathrm{O}_{6}\right)_{m}(m=$ 1-13)," Journal of Molecular Modeling, vol. 12, no. 5, pp. 551-558, 2006.

[21] P. Putaj and F. Lefebvre, "Polyoxometalates containing late transition and noble metal atoms," Coordination Chemistry Reviews, vol. 255, no. 15-16, pp. 1642-1685, 2011.

[22] M. Cindrić, Z. Veksli, and B. Kamenar, "Polyoxomolybdates and polyoxomolybdovanadates-from structure to functions," Croatica Chemica Acta, vol. 82, no. 2, pp. 345-362, 2009.

[23] P. Yin, D. Li, and T. Liu, "Solution behaviors and self-assembly of polyoxometalates as models of macroions and amphiphilic polyoxometalate-organic hybrids as novel surfactants," Chemical Society Reviews, vol. 41, no. 22, pp. 7368-7383, 2012.

[24] F. J. Arnaiz, G. B. Kauffman, and S. D. Pennington, "Dichlorodioxobis(dimethylsulphoxide)-molybdenum(VI)," Inorganic Syntheses, vol. 31, pp. 246-247, 1997.

[25] S. K. Mandal, L. K. Thompson, M. J. Newlands, and E. J. Gable, "Structural, magnetic, and electrochemical studies on macrocylic dicopper(II) complexes with varying chelate ring size," Inorganic Chemistry, vol. 28, no. 19, pp. 3707-3713, 1989.

[26] G. M. Sheldrick and M. George, "A short history of SHELX," Acta Crystallographica Section A, vol. 64, pp. 112-122, 2008.

[27] C. K. Johnson, Crystallographic Computing, edited by: F. R. Ahmed, S. R. Hall, C. P. Huber, Munksgaard, Copenhagen, Denmark, 1970.

[28] N. H. Pilkington and R. Robson, "Complexes of binucleating ligands. 3. Novel complexes of a macrocyclic binucleating ligand," Australian Journal of Chemistry, vol. 23, no. 11, pp. 22252236, 1970.

[29] H. Wada, K. Motoda, M. Ohba, H. Sakiyama, N. Matsumoto, and H. Okawa, "Di(phenoxo)-bridged dinuclear $\mathrm{Mn}_{2}(\mathrm{II}, \mathrm{II})$ and $\mathrm{Mn}_{2}$ (II,III) complexes of macrocyclic ligands-structure, properties, and catalase-like function," Bulletin of the Chemical Society of Japan, vol. 68, no. 4, pp. 1105-1114, 1995.

[30] D. Luneau, J. M. Savariault, P. Cassoux, and J. P. Tuchagues, "Polynuclear manganese(II) complexes with robsontype ligands-synthesis, characterization, molecular-structure, and magnetic-properties," Journal of Chemical Society, Dalton Transactions, no. 5, pp. 1225-1235, 1988. 
[31] H.-R. Chang, S. K. Larsen, P. D. W. Boyd, C. G. Pierpont, and D. N. Hendrickson, "Valence trapping in mixed-valence manganese(II)-manganese(III) complexes of a macrocyclic binucleating ligand," Journal of the American Chemical Society, vol. 110, no. 14, pp. 4565-4576, 1988.

[32] M. Mikuriya, K. Nakadera, and T. Tokii, "Novel eliminationreaction of a hydroxyethyl group in a manganese complexformation of a binuclear manganese(II) complex with a Robson-type macrocyclic ligand," Inorganica Chimica Acta, vol. 194, no. 2, pp. 129-131, 1992.

[33] R. B. Samulewski, J. C. da Rocha, R. Stieler et al., "Supramolecular assembly of new heteropolymetalic molecules based on tetraiminodiphenolate macrocycle and hexacyanometallate anions: magnetostructural and spectroscopic properties," Polyhedron, vol. 30, no. 12, pp. 1997-2006, 2011.

[34] K. Nakamoto, Infrared and Raman Spectra of Inorganic and Coordination Compounds, part B, Wiley, 5th edition, 1997.

[35] H. Vrubel, M. Hörner, E. D. R. Crespan, S. Nakagaki, and F. S. Nunes, "Synthesis and crystal structure of dichlorobis(dimethylsulfoxide)oxoperoxo molybdenum(VI)," Zeitschrift für Anorganische und Allgemeine Chemie, vol. 634, no. 11, pp. 18391841, 2008.

[36] B. Dutta, B. Adhikary, P. Bag, U. Flörke, and K. Nag, "Organized assemblies of lead(II) complexes of a tetraiminodiphenol macrocyclic ligand: manifestation of weak metal-anion interactions and the directional influence of anions," Journal of the Chemical Society, Dalton Transactions, no. 13, pp. 2760-2767, 2002.

[37] S. Yao, Z. Zhang, Y. Li, and E. Wang, “Two dumbbell-like polyoxometalates constructed from capped molybdovanadate and transition metal complexes," Inorganica Chimica Acta, vol. 363, no. 10, pp. 2131-2136, 2010.

[38] W. G. Klemperer and B. Zhong, "Synthesis and characterization of the polyoxoanion-supported $\mathrm{Ru}^{\mathrm{I}}-\mathrm{Ru}^{\mathrm{I}}$ tetracarbonyls $\left[\left(\mathrm{P}_{3} \mathrm{O}_{9}\right)_{2} \mathrm{Ru}_{2}(\mathrm{CO})_{4}\right]^{4-}$ and $\left[\left(\mathrm{Cp}^{*} \mathrm{TiW}_{5} \mathrm{O}_{18}\right)_{2} \mathrm{Ru}_{2}(\mathrm{CO})_{4}\right]^{4-}$," Inorganic Chemistry, vol. 32, no. 25, pp. 5821-5826, 1993. 

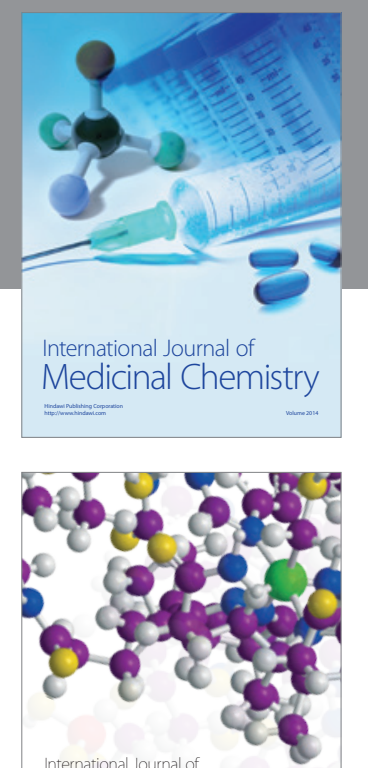

\section{Carbohydrate} Chemistry

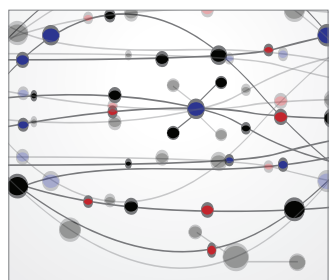

The Scientific World Journal
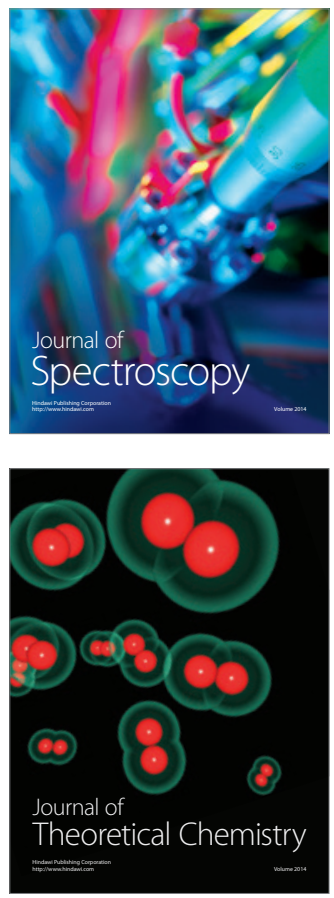
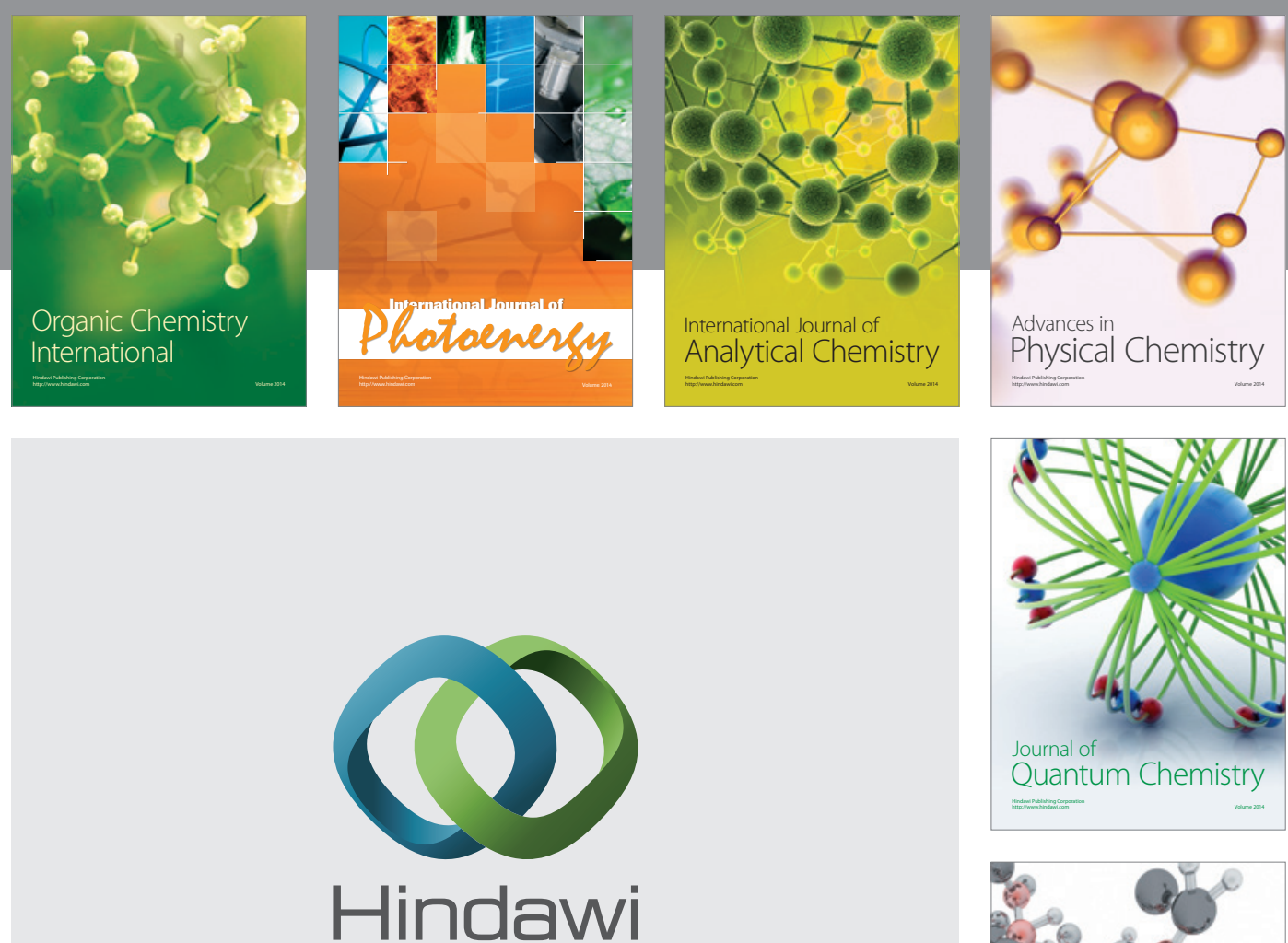

Submit your manuscripts at

http://www.hindawi.com

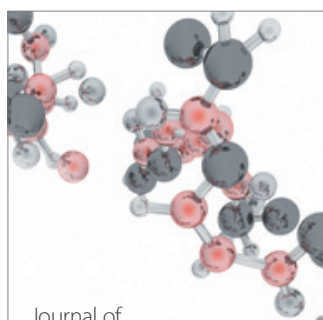

Analytical Methods

in Chemistry

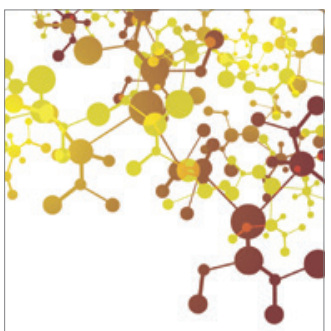

Journal of

Applied Chemistry

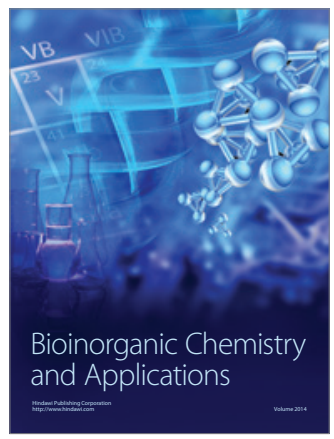

Inorganic Chemistry
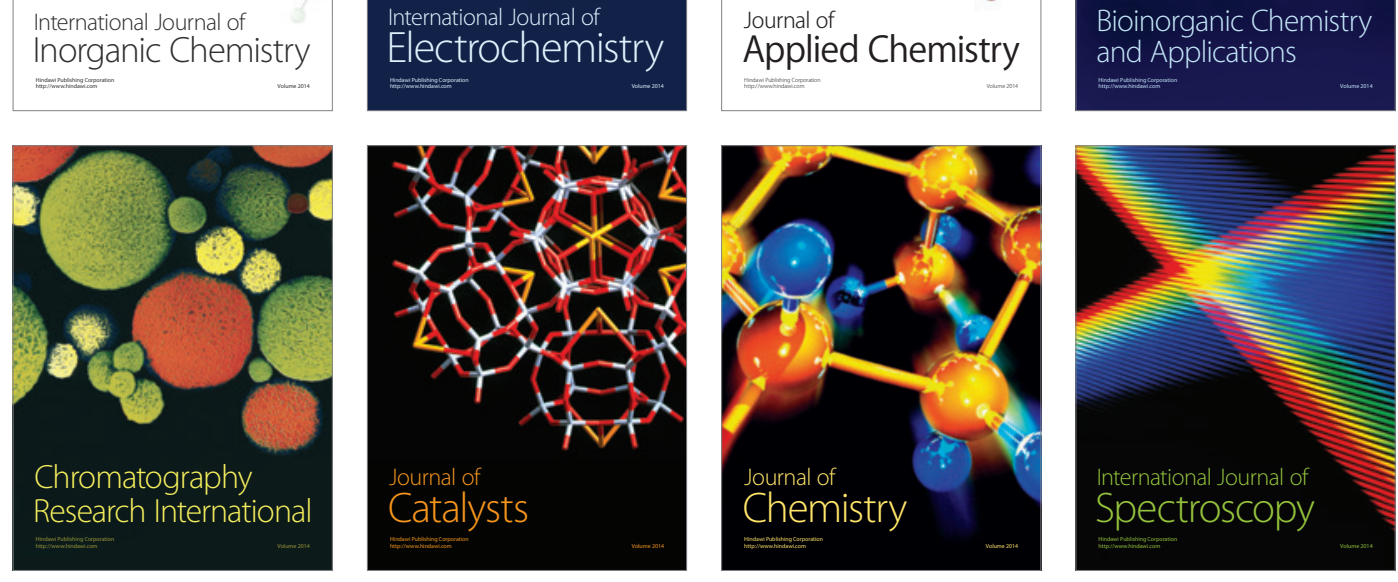